ARTICLE

DOI: $10.1038 / s 41467-018-04888-0$

\title{
Systematic design of superaerophobic nanotube- array electrode comprised of transition-metal sulfides for overall water splitting
}

\author{
Haoyi Li (10 ${ }^{1}$, Shuangming Chen ${ }^{2}$, Ying Zhang ${ }^{3}$, Qinghua Zhang ${ }^{4}$, Xiaofan Jia ${ }^{5}$, Qi Zhang ${ }^{1}$, Lin Gu ${ }^{4}$, Xiaoming Sun ${ }^{3}$,
} Li Song $^{2} \&$ Xun Wang ${ }^{1}$

Great attention has been focused on the design of electrocatalysts to enable electrochemical water splitting-a technology that allows energy derived from renewable resources to be stored in readily accessible and non-polluting chemical fuels. Herein we report a bifunctional nanotube-array electrode for water splitting in alkaline electrolyte. The electrode requires the overpotentials of $58 \mathrm{mV}$ and $184 \mathrm{mV}$ for hydrogen and oxygen evolution reactions respectively, meanwhile maintaining remarkable long-term durability. The prominent performance is due to the systematic optimization of chemical composition and geometric structure principally-that is, abundant electrocatalytic active sites, excellent conductivity of metallic $1 \mathrm{~T}^{\prime}$ $\mathrm{MoS}_{2}$, synergistic effects among iron, cobalt, nickel ions, and the superaerophobicity of electrode surface for fast mass transfer. The electrode is also demonstrated to function as anode and cathode, simultaneously, delivering $10 \mathrm{~mA} \mathrm{~cm}^{-2}$ at a cell voltage of $1.429 \mathrm{~V}$. Our results demonstrate substantial improvement in the design of high-efficiency electrodes for water electrolysis.

\footnotetext{
${ }^{1}$ Key Lab of Organic Optoelectronics and Molecular Engineering, Department of Chemistry, Tsinghua University, Beijing 100084, China. ${ }^{2}$ National Synchrotron Radiation Laboratory, CAS Center for Excellence in Nanoscience, University of Science and Technology of China, Hefei 230029, China. ${ }^{3}$ State Key Laboratory of Chemical Resource Engineering, Beijing Advanced Innovation Center for soft Matter Science and Engineering, College of Energy, Beijing University of Chemical Technology, Beijing 100029, China. ${ }^{4}$ Institute of Physics Chinese Academy of Sciences, Beijing National Laboratory for Condensed Matter Physics, Beijing 100190, China. ${ }^{5}$ Department of Chemistry, University of Virginia, Charlottesville, VA 22904, USA. Correspondence and requests for materials should be addressed to X.W. (email: wangxun@mail.tsinghua.edu.cn)
} 
$\mathrm{D}$ riven by the exigent demand for sustainable and renewable energy sources, a huge effort has been contributed to the development of efficient and accessible energy conversion technologies ${ }^{1-3}$. Electrochemical water splitting-a costeffective and environmentally friendly technology for hydrogen evolution from electricity-has attracted great attention as a promising pathway to decrease social dependence on fossil fuels ${ }^{4-6}$. The synthesis and application of low-cost, highperformance electrocatalysts for water electrolysis are quite necessary to make water splitting become a functional and practical technology ${ }^{7-9}$. As a means of lowering the driving overpotential and increasing the efficiency of catalytic water splitting, there are several main aspects that deserve attention in the development of electrode materials. First, enhancing the intrinsic activity of catalytic sites in electrocatalysts requires an optimization of the Gibbs free energy of adsorption for reactants to speed the rate-determining step in the overall reactions ${ }^{10-14}$. Second, the enhanced conductivity of electrode materials is significant to enable fast charge transfer, a requirement for which metallic materials have demonstrated superior ability ${ }^{15-17}$. Third, the optimization of mass transfer properties has a tremendous effect on the ultimate efficiency of electrocatalysts. Innovative nanoarray architectures have great potential to facilitate the dissipation of as-generated gas bubbles from surface of the electrode and accelerate the reactions on cathode and anode-the hydrogen and oxygen evolution reaction (HER and OER) ${ }^{18,19}$. Finally, the increased density of electrocatalytic active sites in electrocatalysts allows for the maximization of limited electrode surface areaporous nanostructures have a proven ability to facilitate increased surface area $^{20,21}$.

With due consideration for the design principles enumerated above, we prepared a hybrid polymetallic sulfide nanotube-array electrode for water splitting via integrated compositional and geometric structural design. Metallic monoclinic 1T' phase $\mathrm{MoS}_{2}$ was employed for its excellent electrode kinetics, fast charge transfer, and remarkable intrinsic electrocatalytic HER activity $^{22-24}$. Trimetallic iron, cobalt, nickel-based ( $\mathrm{Fe}, \mathrm{Co}$, Nibased) sulfides were utilized for their inherent and adjustable OER reactivity (a result of synergistic effects between metal ions) 25-27. Finally, nanotube-array architectures were exploited for their porosity, high surface area, and uneven surface characteristics - a way to maximize catalytic active site density-and these morphological features provide the intriguing possibility of displacing as-generated gas bubbles from surface of the electrode simply-a feature which is known as superaerophobicity. Superaerophobic behavior would allow greater contact between electrode and electrolyte, and thus promote efficient mass transfer ${ }^{18}$.

In this work, the hybrid nanotube arrays (denoted as FeCoNiHNTAs) are synthesized from ternary Fe, Co, Ni-based layered double hydroxide nanowire arrays (FeCoNi-LDH-NWAs) supported on $\mathrm{Ni}$ foam substrate. The FeCoNi-HNTAs show remarkable activity and long-playing durability in electrocatalytic
HER and OER. Notably, FeCoNi-HNTAs deliver a current density of $10 \mathrm{~mA} \mathrm{~cm}^{-2}$ at an overpotential of $58 \mathrm{mV}$ for the HER and $184 \mathrm{mV}$ for the OER, respectively, while demonstrating outstanding durability $\left(200 \mathrm{~mA} \mathrm{~cm}^{-2}\right.$ for $80-\mathrm{h}$ continuous operation). The low Tafel slopes of $37.5 \mathrm{mV} \mathrm{dec}^{-1}$ and $49.9 \mathrm{mV} \mathrm{dec}^{-1}$ for HER and OER demonstrate the fast reaction kinetics. Additionally, we utilize FeCoNi-HNTAs in a water splitting system as anode and cathode simultaneously, achieving a current density of $10 \mathrm{~mA} \mathrm{~cm}^{-2}$ at a cell voltage of $1.429 \mathrm{~V}$ in alkaline media. Synergistic effects among $\mathrm{Fe}, \mathrm{Co}$, and $\mathrm{Ni}$ ions are investigated by synchrotron radiation-based soft X-ray absorption spectroscopy (sXAS). Under-electrolyte superaerophobic and superhydrophilic features of the electrode surface are confirmed by adhesive force and contact angle measurements. Furthermore, ex situ and in situ synchrotron radiation-based extended X-ray absorption fine structure (EXAFS) characterizations are carried out to testify the presence and phase stability of $1 \mathrm{~T}^{\prime} \mathrm{MoS}_{2}$.

\section{Results}

Synthesis and characterization of FeCoNi-HNTAs. Taking the advantages into consideration, such as high surface area, superb electrical conductivity and low cost ${ }^{17}$, Ni foam (Supplementary Fig. 1) was employed as the substrate for the synthesis of the expected electrode. FeCoNi-HNTAs, as schematically shown in Fig. 1, were synthesized through an accessible two-step solvothermal method (see details in Methods). First, FeCoNi-LDHNWAs were prepared via a hydrolysis route ${ }^{28,29}$. Field-emission scanning electron microscope (FESEM) images (Fig. 2a) show the nanowire morphology bound to the substrate along with different directions and uniform diameter size of approximately $150 \mathrm{~nm}$. The X-ray diffraction (XRD) pattern confirms the crystal structures of the as-prepared LDH nanowires (Supplementary Fig. 2). We also performed the energy-dispersive X-ray (EDX) elemental mapping measurement and found the uniform distribution of the five elements (Supplementary Fig. 3), which further indicated the successful synthesis of trimetal LDH nanowires. In the second step, FeCoNi-LDH-NWAs, regarded as the self-sacrificing templates, and ammonium tetrathiomolybdate $\left(\left(\mathrm{NH}_{4}\right)_{2} \mathrm{MoS}_{4}\right)$ were used as precursors for the synthetic reaction, where defined quantity of hydrazine hydrate (HZH) was also added. The FeCoNi-HNTAs were accessibly obtained in a large-scale level. Propagating the randomness of FeCoNi-LDH-NWAs, FeCoNiHNTAs irregularly align on Ni foam and exhibit excellent dispersity and uniformity as shown in a larger scale image (Fig. 2b). The disorder contributes to higher porosity, thus exposing more catalytic active sites and facilitating mass transfer ${ }^{30,31}$. The structural generation process of the hybrid nanotubes from nanowires was studied (Supplementary Fig. 4) and the growth mechanism is considered as the Kirkendall cavitation ${ }^{32,33}$. The above synthetic strategy demonstrates a great achievement on morphology design for hybrid nanotube arrays. We further applied this method to the other two analogous systems

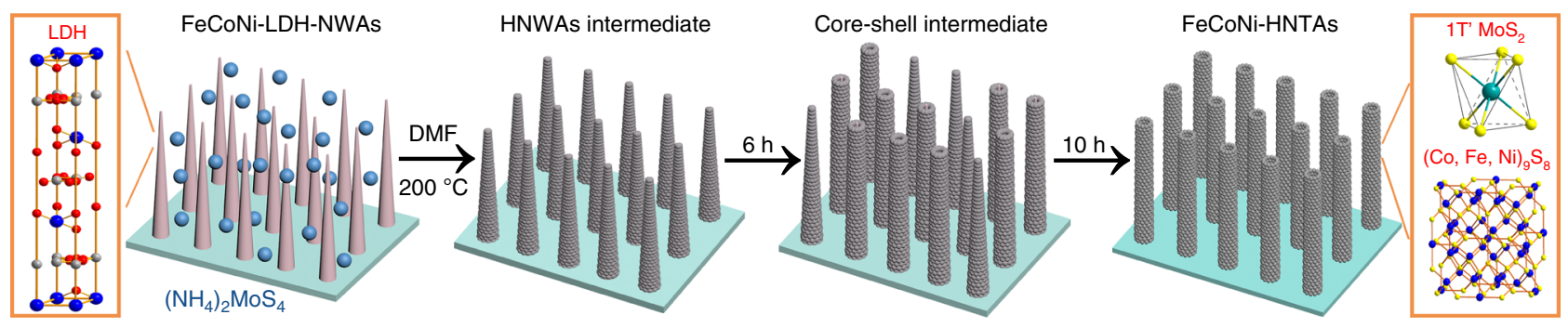

Fig. 1 Schematic representation of the synthetic process of FeCoNi-HNTAs. FeCoNi-LDH-NWAs on Ni foam and $\left(\mathrm{NH}_{4}\right)_{2} \mathrm{MoS}_{4}$ are employed as the

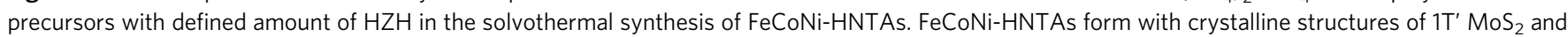
$(\mathrm{Co}, \mathrm{Fe}, \mathrm{Ni})_{9} \mathrm{~S}_{8}$ via the Kirkendall cavitation 

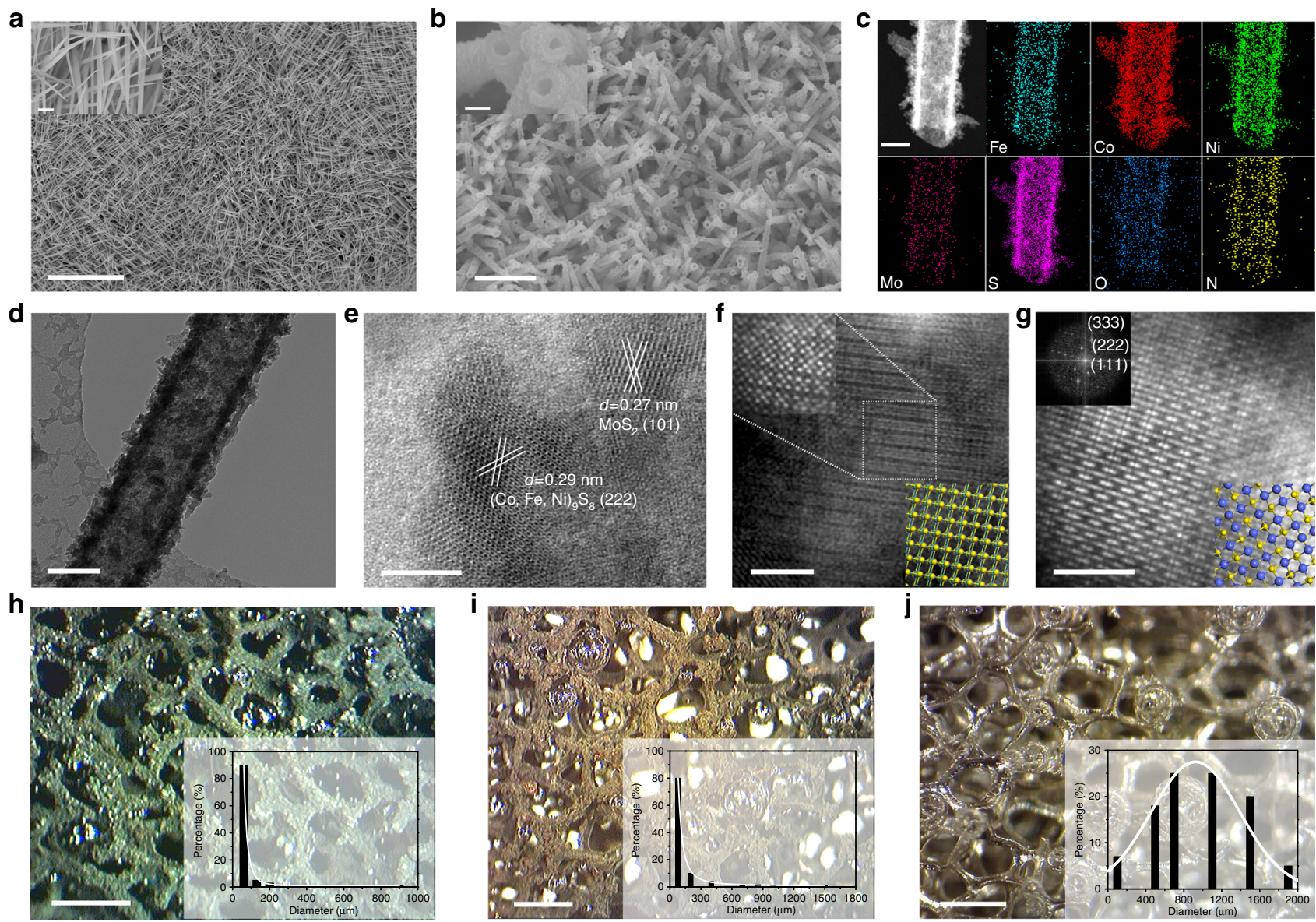

Fig. 2 Morphological and structural characterizations and bubble releasing behaviors. a, b FESEM images demonstrating the uniformity of the as-prepared FeCoNi-LDH-NWAs and FeCoNi-HNTAs respectively as a large scale view. The insets of $(\mathbf{a}, \mathbf{b})$ are the corresponding magnified FESEM images and scale bars are 500 and $200 \mathrm{~nm}$, respectively. c STEM and EDX elemental mapping spectra exhibiting the hollow nature, uneven tube wall, and uniform distribution of $\mathrm{Fe}$ (cyan), Co (red), Ni (green), Mo (pink), S (magenta), O (blue), and N (yellow) elements. d TEM image, e HRTEM image. The lattice fringes with the spacing of $0.27 \mathrm{~nm}$ and $0.29 \mathrm{~nm}$ are in agreement with the (101) and (222) planes of $\mathrm{MoS}_{2}$ and $\left(\mathrm{Co}_{0}, \mathrm{Fe}, \mathrm{Ni}\right)_{9} \mathrm{~S}_{8}$, respectively. $\mathbf{f}, \mathbf{g}$ AC-STEM images of $1 \mathrm{~T}^{\prime} \mathrm{MoS}_{2}$ and $(\mathrm{Co}, \mathrm{Fe}, \mathrm{Ni})_{9} \mathrm{~S}_{8}$ in $\mathrm{FeCoNi-HNTAs}$, respectively. The upper image of inset of $\mathbf{f}$ displays the Mo clusters with tetragonal symmetry marked by short dash line square in $\mathbf{f}$. The corresponding FFT pattern of $(\mathrm{Co}, \mathrm{Fe}, \mathrm{Ni})_{9} \mathrm{~S}_{8}$ is shown as the upper image of inset of $\mathbf{g}$. The lower images of the insets of $\mathbf{f}, \mathbf{g}$ are the corresponding crystal structures, where yellow, cyan, and blue balls represent $\mathrm{S}, \mathrm{Mo}$, and $\mathrm{Co}$ (or Fe, Ni) atoms. h, i, $\mathbf{j}$ Digital photos demonstrating the bubble releasing behaviors on the surface of FeCoNi-HNTAs, FeCoNi-LDH-NWAs, and bare Ni foam for HER. The insets are the corresponding size distribution statistics of releasing bubbles. Scale bars: a $10 \mu \mathrm{m} ; \mathbf{b} 2 \mu \mathrm{m} ; \mathbf{c} 100 \mathrm{~nm} ; \mathbf{d} 100 \mathrm{~nm} ; \mathbf{e} 5 \mathrm{~nm} ; \mathbf{f}, \mathbf{g} 2 \mathrm{~nm} ; \mathbf{h}, \mathbf{i}$, j $2 \mathrm{~mm}$

(Supplementary Fig. 5). The hybrid nanotube and nanosheet arrays (CoNi-HNTAs and NiFe-HNSAs) synthesized from corresponding bimetal LDH nanoarrays, Co, Ni-based layered double hydroxides nanowire arrays (CoNi-LDH-NWAs) and $\mathrm{Fe}, \mathrm{Ni}-$ based layered double hydroxides nanosheet arrays (NiFe-LDHNSAs), verify the universality of this method. Furthermore, there were also two electrodes that were manufactured in the same method as FeCoNi-HNTAs for comparison (synthetic details shown in Methods). One is the electrode that $\mathrm{MoS}_{2}$ directly grows on the Ni foam without the precursor of $\mathrm{FeCoNi}$-LDH-NWAs (Supplementary Fig. 6a), denoted as $\mathrm{MoS}_{2} / \mathrm{Ni}$ Foam. The other is the electrode showing porous nanotube array morphology that FeCoNi-LDH-NWAs are sulfurated by thioacetamide (TAA) instead of $\left(\mathrm{NH}_{4}\right)_{2} \mathrm{MoS}_{4}$ (Supplementary Fig. 6b), denoted as FeCoNiS-NTAs.

When focusing on a single nanotube in FeCoNi-HNTAs (Fig. 2b, c, d), the diameter size is around $150 \mathrm{~nm}$ and the thickness of the tube wall ranges from approximately 30 to $80 \mathrm{~nm}$. Hollow characteristic and high degree of surface roughness can be distinctly observed (Supplementary Fig. 7), which proliferate the active surface area and expose more catalytic active sites.
Meanwhile, EDX elemental mapping spectra (Fig. 2c) elucidate the elementary composition of FeCoNi-HNTAs. Besides, the presented seven elements uniformly distribute in a single tube. We also carried out the EDX spectra (Supplementary Fig. 8) to illustrate the elemental ratios, that showed Fe: $\mathrm{Co}$ : Ni was about 1:5:3 and the percent proportions of Mo in FeCoNi-HNTAs reached about $11.9 \%$, which was consistent with the feed ratios. Moreover, integrating high-resolution transmission electron microscopy (HRTEM) image (Fig. 2e) and corresponding XRD pattern (Supplementary Fig. 9), the characteristic lattice fringes of (101) planes in $\mathrm{MoS}_{2}$ with inter-planar distances of $0.27 \mathrm{~nm}$ were exhibited as well as (222) planes of $(\mathrm{Co}, \mathrm{Fe}, \mathrm{Ni})_{9} \mathrm{~S}_{8}$ with interplanar spacing of $0.29 \mathrm{~nm}$, which is confirmed by the crystalline nature of FeCoNi-HNTAs. The HRTEM image further demonstrates successful formation of the hybrid nanostructures that presents the combination and no boundaries of the two compositions. Typical atomic resolution aberration-corrected scanning TEM (AC-STEM) images clarify the presence of $1 \mathrm{~T}^{\text {' }}$ $\mathrm{MoS}_{2}$ and $(\mathrm{Co}, \mathrm{Fe}, \mathrm{Ni})_{9} \mathrm{~S}_{8}$, respectively. The superlattices of $1 \mathrm{~T}^{\prime}$ $\mathrm{MoS}_{2}$ with Mo clusters could be clearly visualized in Fig. 2f, distinctly exhibiting expected tetragonal symmetry of atomic 
arrangement ${ }^{34}$. Cubic symmetry of the crystals can also be apparently distinguished in Fig. $2 \mathrm{~g}$ and the corresponding fast Fourier transform (FFT) pattern is indexed unequivocally to (Co, $\mathrm{Fe}, \mathrm{Ni})_{9} \mathrm{~S}_{8}{ }^{35}$. These characterization results demonstrate our compositional and structural design for the hybrid system, whose superiorities mentioned above are considered to be the steppingstone for the enhancement of electrocatalytic performance.

In addition to the construction of chemical compositions, visual behavior of as-generated gas bubbles releasing from the surface of FeCoNi-HNTAs demonstrates the morphological advancements of FeCoNi-HNTAs in electrocatalytic water splitting. Specifically, the bubble releasing behaviors during HER and OER can directly reflect the mass transfer efficiency ${ }^{18}$. A high-speed camera with a charge-coupled device recorded the bubble release during a galvanostatic scan for HER and OER at the current density of $20 \mathrm{~mA} \mathrm{~cm}^{-2}$. As shown in Fig. $2 \mathrm{~h}, \mathrm{i}, \mathrm{j}$, distinct comparison between FeCoNi-HNTAs, FeCoNi-LDHNWAs and bare Ni foam for as-formed gas bubbles releasing behaviors proves superior mass transfer on nanoarray electrode than the flat electrode, where the releasing bubbles have the major size distribution of less than $100 \mu \mathrm{m}$ and around $1000 \mu \mathrm{m}$, respectively. Other bubble releasing phenomena are displayed in Supplementary Fig. 10. The quick releasing process of gas bubbles on nanoarray electrode verifies that the architectures we developed possesses quite fascinating surface feature for fast mass transfer, suggesting that it is a promising candidate for scale-up utilization in practical applications.

In-depth characterizations were carried out to illustrate the fine structures and chemical valence states of the hybrid nanostructures. In this solvothermal system, we used $\mathrm{HZH}$ as inductive agent and electron donor to achieve the formation of metallic $1 \mathrm{~T}^{\prime} \mathrm{MoS}_{2}{ }^{21}$. To identify its phase, the local bond nature was investigated by EXAFS at Mo K-edge. According to the normalized X-ray absorption near edge structure (XANES) spectrum from EXAFS (Fig. 3a), the preedge peak of FeCoNi-HNTAs shifts to higher energy than that of the standard $2 \mathrm{H} \mathrm{MoS}_{2}$ foil, that is due to larger oxidation degree of $\mathrm{MoS}_{2}$. In the meantime, $\mathrm{MoS}_{2}$ in FeCoNi-HNTAs possesses obvious difference of white line peak, suggesting the different local atomic arrangements. The FT profile comparison of EXAFS data at Mo K-edge in R-space (Fig. 3b) exhibits distinct downshift of MoMo bond peak in FeCoNi-HNTAs, demonstrating decreasing bond length from 3.16 to $2.79 \AA$ (Supplementary Table 1), which corresponds to the characteristic peak of Mo-Mo bond in 1T' $\mathrm{MoS}_{2}{ }^{36}$. This result also proves the stability of $1 \mathrm{~T}^{\prime} \mathrm{MoS}_{2}$ in FeCoNiHNTAs under ambient environment (Supplementary Note 1). Besides, the evidently higher intensity of $\mathrm{Mo}-\mathrm{O} / \mathrm{N}$ bond peak should be due to the coordination with $\mathrm{HZH}$ and slight oxidation from air. The fitting curve for FT profiles is exhibited in Supplementary Fig. 11, which matches well with the experimental data. The X-ray photoelectron spectroscopy (XPS) spectrum (Fig. 3c) of Mo 3d and S $2 \mathrm{~s}$ regions of $\mathrm{MoS}_{2}$ in FeCoNi-HNTAs shows the fitting curve from characteristic peaks of 1T' (228 and $231.2 \mathrm{eV}$ ) and $2 \mathrm{H}$ phase $(229 \text { and } 232 \mathrm{eV})^{37}$, resulting in the major proportion of $1 \mathrm{~T}^{\prime} \mathrm{MoS}_{2}$ in FeCoNi-HNTAs. The above illustration completely testifies the $\mathrm{MoS}_{2}$ in FeCoNi-HNTAs as 1T' phase, which can provide higher density of electrocatalytic active sites for HER and greatly facilitate electrical conductivity of the electrode. Moreover, the high-resolution XPS spectra comparison (Supplementary Fig. 12) was performed to demonstrate the interaction between the two compositions in FeCoNi-HNTAs. Compared with that of $\mathrm{MoS}_{2} / \mathrm{Ni}$ Foam, the downshift about $0.8 \mathrm{eV}$ of the peak positions of FeCoNi-HNTAs can be obviously observed, which elucidates the charge transfer from $\mathrm{Fe}, \mathrm{Co}$, Ni-based sulfides to $\mathrm{MoS}_{2}$ to facilitate the phase transition from $2 \mathrm{H}$ to $1 \mathrm{~T}^{\prime}$ phase $\mathrm{e}^{21,37}$. This interaction between the two compositions further indicates the hybrid material nature of FeCoNi-HNTAs.
The chemical valence states of $\mathrm{Fe}, \mathrm{Co}$, and $\mathrm{Ni}$ in $\mathrm{FeCoNi}$ HNTAs was investigated by high-resolution XPS ${ }^{38}$. As shown in Fig. $3 \mathrm{~d}$, there are three kinds of characteristic peaks, belonging to $\mathrm{Fe}-\mathrm{S}(706.7 \mathrm{eV})^{39}, \mathrm{Fe}^{2+}(710.4 \mathrm{eV})$, and $\mathrm{Fe}^{3+}(712.8 \mathrm{eV}) 2 \mathrm{p}$ regions, that enable the fitting curve to match the original signal well. The broad peak representing $\mathrm{Fe}^{2+}$ and $\mathrm{Fe}^{3+}$ demonstrates the presence of oxidation states of iron. As for the XPS spectrum of Co $2 \mathrm{p}$ regions (Fig. $3 \mathrm{e}$ ), the main peak can be split into two distinctive peaks of $\mathrm{Co}^{3+}(780.7 \mathrm{eV})$ and $\mathrm{Co}^{2+}(782.1 \mathrm{eV})$, of which the shoulder at lower binding energy is corresponding to the Co-S peak $(778.0 \mathrm{eV})^{40}$. Similarly, both of $\mathrm{Ni}^{2+}(855.0 \mathrm{eV})$ and $\mathrm{Ni}^{3+}(856.1 \mathrm{eV})$ could be measured in the final product according to the XPS spectrum of $\mathrm{Ni} 2 \mathrm{p}$ regions (Fig. $3 \mathrm{f}$ ). Therefore, it is revealed that the high and low oxidation states of $\mathrm{Fe}, \mathrm{Co}$, and $\mathrm{Ni}$ coexist in FeCoNi-HNTAs.

For the first row transition metal-based compounds, sXAS is performed for direct detection of the $3 \mathrm{~d}$ valence states of the metals via dipole selection rules. The $2 \mathrm{p}$ core electrons enable the excitation to be transferred into the empty $3 \mathrm{~d}$ orbitals. This transition process allows the exploration of the $3 \mathrm{~d}$ electrons with high-intensity, which is beneficial to acquire a comprehensive understanding and systematically optimize materials for electrocatalysis. Here we mainly focus on the $\mathrm{L}_{3}$ regions at $\mathrm{Fe}, \mathrm{Co}$, and $\mathrm{Ni}$ L-edge sXAS recorded in the total electron yield (TEY) mode to illustrate the interaction among them. At Fe $\mathrm{L}_{3}$ edge (Fig. $3 \mathrm{~g}$ ), there are two groups of peaks around $706.7 \mathrm{eV}$ and $708.1 \mathrm{eV}$, corresponding to the fingerprints of $\mathrm{Fe}^{2+}$ and $\mathrm{Fe}^{3+}$, respectively ${ }^{41}$. Compared with NiFe-HNSAs, the amount of $\mathrm{Fe}^{3+}$ increases obviously in FeCoNi-HNTAs, indicating Co ions can adjust the electronic state of Fe to favor the high valence state. Friebel et al. have reported that $\mathrm{Fe}^{3+}$ sites are indeed highly active for OER, because the intermediate of OER process has quite low Gibbs free energy of adsorption on Fe sites. This result indicates that Co behavior has a positive effect on the enhancement of OER activity $^{25}$. When referring to $\mathrm{Fe}$ incorporation impact, the comparison of Co L-edge sXAS between FeCoNi-HNTAs and CoNi-HNTAs is exhibited in Fig. 3h. A small shoulder at 780.4 $\mathrm{eV}$ of $\mathrm{FeCoNi}$-HNTAs is owing to the distinctive peak of the $\mathrm{Co}^{3+}$ ions located at octahedral sites, which demonstrates that the participation of Fe in our hybrid system can tune the crystal-field coordination of Co ions. It have been investigated that $\mathrm{Co}^{3+}$ ions located at octahedral sites are the active centers for OER rather than the $\mathrm{Co}^{2+}$ ions at tetrahedral sites $(778.2 \mathrm{eV})$ and the interaction between $\mathrm{Fe}$ and $\mathrm{Co}$ ions is considered to improve the intrinsic activity for OER and affects chemical and structural stability $26,42,43$. Therefore, the synergetic effect of Fe and Co ions in our hybrid system is beneficial for the enhancement of OER performance. Besides, $\mathrm{Fe}$ and $\mathrm{Co}$ are demonstrated to influence the local electronic structure of $\mathrm{Ni}$ cations according to the $\mathrm{Ni} \mathrm{L-}$ edge sXAS (Fig. 3i). In contrast with NiFe-HNSAs and CoNiHNTAs, FeCoNi-HNTAs apparently show a shoulder peak at $852.8 \mathrm{eV}$ in agreement with the fingerprint of $\mathrm{Ni}^{3+}$, which is regarded as electrocatalytic sites with higher activity than $\mathrm{Ni}^{2+}$ (sXAS $\mathrm{L}_{3}$-edge peak at $850.7 \mathrm{eV}$ ) for $\mathrm{OER}^{25,44}$. Thus the interaction between $\mathrm{Fe}, \mathrm{Co}$, and $\mathrm{Ni}$ in our hybrid system has a great significance on the improvement of OER electrocatalytic activity. Based on the analyses of the fine structures and chemical valence states of the FeCoNi-HNTAs, it is summarized that synergistic effects can be verified among $\mathrm{Fe}, \mathrm{Co}$, and $\mathrm{Ni}$ ions, which is extraordinarily critical to promote OER electrocatalysis.

Under-electrolyte superaerophobicity of FeCoNi-HNTAs. To identify the origin of nanoarray structural advantages for bubble release from the electrode surface with ease, surface superaerophobicity of the as-prepared electrodes was investigated by 

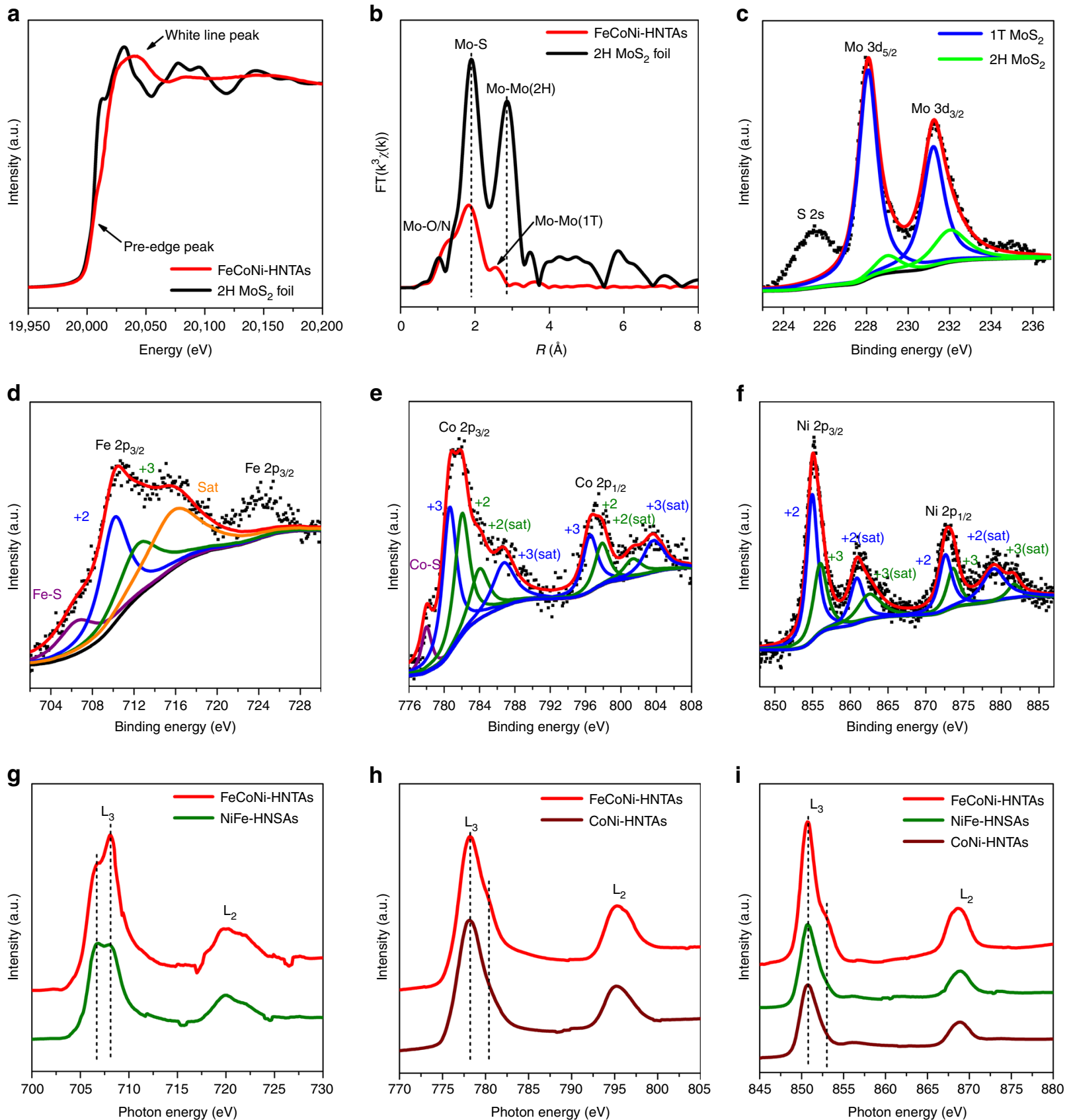

Fig. 3 In-depth compositional and structural analyses of FeCoNi-HNTAs. a, $\mathbf{b}$ The normalized ex situ XANES spectra and corresponding $\mathrm{k}^{3}$-weighted FT profile in R-space from EXAFS at Mo K-edge of FeCoNi-HNTAs. c-f High-resolution XPS spectra of Mo 3d, Fe 2p, Co 2p, and Ni 2p regions with fitting curves. g-i Normalized Fe, Co, and Ni L-edge sXAS spectra of FeCoNi-HNTAs and the counterparts in TEY mode

adhesive force of the bubbles to the surface and bubble contact angle measurements in $1 \mathrm{M} \mathrm{KOH}$ media (applied electrolyte for electrocatalytic measurements), in which the wetting ability or contact manner on the under-electrolyte surface is crucial ${ }^{45}$. As shown in Fig. 4a, there is not any adhesive force between the bubble and the surface measured for FeCoNi-HNTAs, which is further demonstrated through the inappreciable deformation of the bubble in the process of the measurement (inset 1-3 of Fig. 4a). Meanwhile, the bubble contact angle reaches $171.0^{\circ} \pm$ $3.4^{\circ}$ on the surface of FeCoNi-HNTAs under electrolyte (inset 4 in Fig. 4a), indicating the remarkable superaerophobicity of FeCoNi-HNTAs. This feature can be attributed to the discontinuous state of the three-phase contact line (TPCL) of the bubbles with surface of the electrode, contributing to the exceptionally low contact region between the bubbles and surface of the electrode and thus low adhesive force ${ }^{18}$. Surface superhydrophilicity of FeCoNi-HNTAs is also displayed in inset 5 of Fig. 4a. The electrolyte droplet infiltrated the electrode immediately and could not be captured by high-speed camera. This excellent superhydrophilicity results in the formation of a wetting film on the surface of the electrode. By increasing the amount of electrolyte, the electrolyte liquid film may reduce the contact region between the bubbles and surface of the electrode and hence decrease the bubble adhesive force. Employing FeCoNiLDH-NWAs, $\mathrm{MoS}_{2} / \mathrm{Ni}$ Foam, bare Ni foam, FeCoNi-HNWAs, CoNi-HNTAs, NiFe-HNSAs, and FeCoNiS-NTAs as contrastive samples (Fig. 4b, c, d, and Supplementary Fig. 13), the values of adhesive force, bubble contact angle under electrolyte, the 

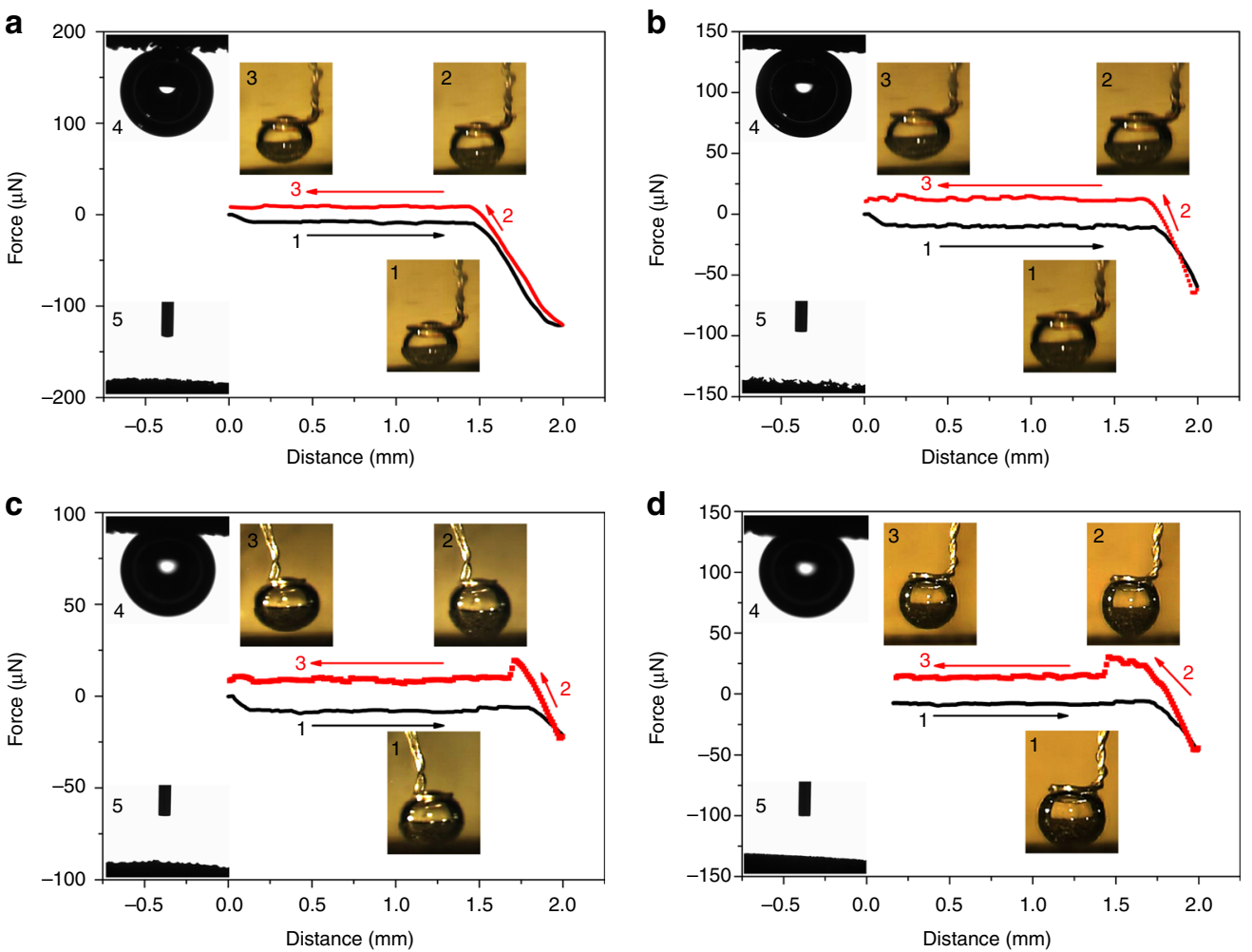

Fig. 4 Under-electrolyte superaerophobic and superhydrophilic measurements. a-d Gas bubble adhesive force measurements of FeCoNi-HNTAs, FeCoNiLDH-NWAs, $\mathrm{MoS}_{2}$ /Ni Foam, and bare Ni foam respectively. FeCoNi-HNTAs and FeCoNi-LDH-NWAs obviously show no bubble adhesive force while the larger bubble adhesive forces are measured on $\mathrm{MoS}_{2} / \mathrm{Ni}$ Foam $(10.6 \pm 1.9 \mu \mathrm{N})$ and bare Ni foam $(16.0 \pm 1.7 \mu \mathrm{N})$. The insets $1-3$ show the bubble states in the corresponding measurement process of adhesive force where process 1 illustrates the electrode surface gets close to the air bubble, process 2 demonstrates the electrode surface leaves the air bubble and process 3 displays the electrode surface separates from the air bubble. The distinct bubble deformation observed in insets 2 of $\mathbf{c}$ and $\mathbf{d}$ further prove the adhesivity of $\mathrm{MoS}_{2} / \mathrm{Ni}$ Foam and bare Ni foam to bubbles. For insets 4 , the bubble contact angles under electrolyte were measured as $171.0^{\circ} \pm 3.4^{\circ}, 156.5^{\circ} \pm 2.9^{\circ}, 146.2^{\circ} \pm 2.1^{\circ}$, and $143.7^{\circ} \pm 2.3^{\circ}$ respectively. Insets 5 show the wetting ability of the electrodes in which $\mathrm{KOH}$ solution droplets can not be captured suggesting the surface superhydrophilicity of the employed electrodes

advancing angle, the receding angle, the corresponding contact angle hysteresis and electrolyte droplets contact angle are all summarized in Supplementary Table 2. It is observed that all of the nanoarray electrodes we explored show prominent superaerophobicity and superhydrophilicity, which manifests the deployed nanoarray electrodes are indeed preponderant in electrocatalysis of gas evolution reaction. The decrease of roughness is embodied in $\mathrm{MoS}_{2} / \mathrm{Ni}$ Foam and bare Ni foam (Supplementary Fig. 6a and Supplementary Fig. 1), which have bulk morphology with large size (more than $500 \mathrm{~nm}$ ) and flat surface respectively. The Wenzel-Cassie transition demonstrates a continuous change of surface wetting behavior with the change of gas contact mode on the interface based on the roughness increase ${ }^{45}$. Therefore, $\mathrm{MoS}_{2} / \mathrm{Ni}$ Foam and bare $\mathrm{Ni}$ foam possess enhanced adhesion ability to bubbles in the solution. We believe that the above consequences can inspire progress in specific architecture of nanoarray electrode with desirable surface superaerophobicity and wetting state, leading to efficient bubble release from the electrode surface for gas evolution reaction.

Evaluation of electrocatalytic water splitting performance. The as-prepared electrodes were directly applied to a typical threeelectrode cell as the working electrode for HER and OER electrocatalysis in $1 \mathrm{M} \mathrm{KOH}$ electrolyte. The $\mathrm{Ag} / \mathrm{AgCl}$ electrode was utilized as the reference electrode and a graphite rod as the counter electrode. Reversible hydrogen electrode (RHE) calibration was also performed (Supplementary Fig. 14) and all of the potentials in the measurements were exhibited vs. RHE. The incipient measurement was performed via cyclic voltammetry for activation and stabilization of the electrodes. For HER, linear sweep voltammetry was first carried out for recording the polarization ability of the as-synthesized electrodes. FeCoNiHNTAs shows remarkably enhanced catalytic activity compared to other employed electrodes (Fig. 5a and Supplementary Fig. $15 \mathrm{a})$, which just needs the overpotentials $\left(\eta_{\mathrm{HER}}\right)$ of $58 \mathrm{mV}$ to afford a current density of $10 \mathrm{~mA} \mathrm{~cm}^{-2}\left(\eta_{\mathrm{HER}}\right.$ for FeCoNi-LDHNWAs, $\mathrm{MoS}_{2}$ /Ni Foam, FeCoNiS-NTAs, bare Ni foam, FeCoNiHNWAs, CoNi-HNTAs, and NiFe-HNSAs are $214 \mathrm{mV}, 181 \mathrm{mV}$, $121 \mathrm{mV}, 322 \mathrm{mV}, 80 \mathrm{mV}, 70 \mathrm{mV}$, and $169 \mathrm{mV}$, respectively). Notably, the HER performance of FeCoNi-HNTAs approaches that of commercial $\mathrm{Pt} / \mathrm{C}$ catalyst loaded on $\mathrm{Ni}$ foam, in which the difference of $\eta_{\text {HER }}$ is only $11 \mathrm{mV}$. The catalytic reaction kinetics is studied by Tafel plot. As it is shown in Fig. 5b, the slope value of Tafel curve of FeCoNi-HNTAs exhibits $37.5 \mathrm{mV} \mathrm{dec}^{-1}$, smaller than that of FeCoNiS-NTAs $\left(59.2 \mathrm{mV} \mathrm{dec}^{-1}\right)$, FeCoNi-LDHNWAs $\left(122.6 \mathrm{mV} \mathrm{dec}^{-1}\right)$, and $\mathrm{MoS}_{2} / \mathrm{Ni}$ Foam $\left(95.2 \mathrm{mV} \mathrm{dec}^{-1}\right)$, verifying the rapid HER catalytic rate. This Tafel slope value recorded on FeCoNi-HNTAs also indicates better inherent catalytic activity for HER from the perspective of reaction mechanism $^{24}$. Supported by conductive substrate, all of the electrodes possess a low level of charge transfer resistance (Supplementary Fig. 16a) proven by the Nyquist plots of electrochemical impedance spectroscopy (EIS). Compared with other contrastive samples, the resistance of FeCoNi-HNTAs is smaller by an order of magnitude due to the composition of metallic $1 \mathrm{~T}^{\prime} \mathrm{MoS}_{2}$. To 
assess the electrochemical active surface area (ECSA), doublelayer capacitance $\left(C_{\mathrm{dl}}\right)$ was measured to roughly calculate the value of ECSA. The current densities at the selected potential from the regions of no Faradaic processes were showed as the
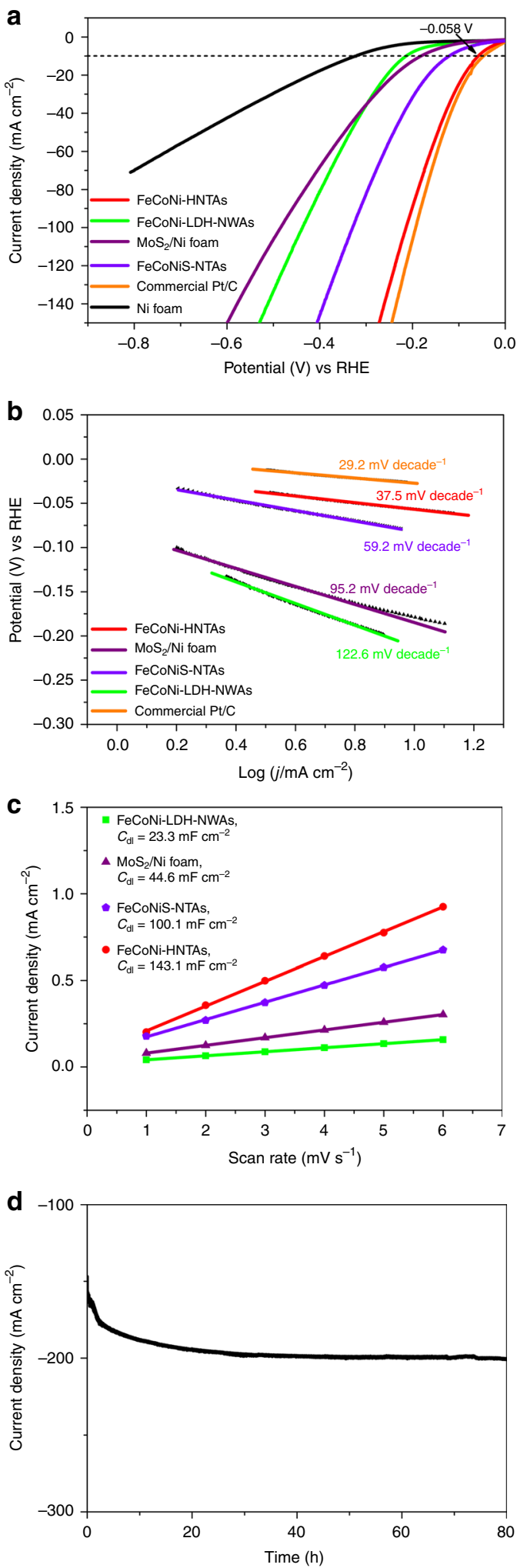

linear correlation with the scan rates (Fig. $5 \mathrm{c}$ and Supplementary Fig. $17 \mathrm{a}, \mathrm{c}, \mathrm{e}, \mathrm{g}$ ) and the slopes of the fitting curves were considered as the $C_{\mathrm{dl}}$. FeCoNi-HNTAs have the largest ECSA value of $3577.5 \mathrm{~cm}^{2}$ among the four samples, suggesting the most
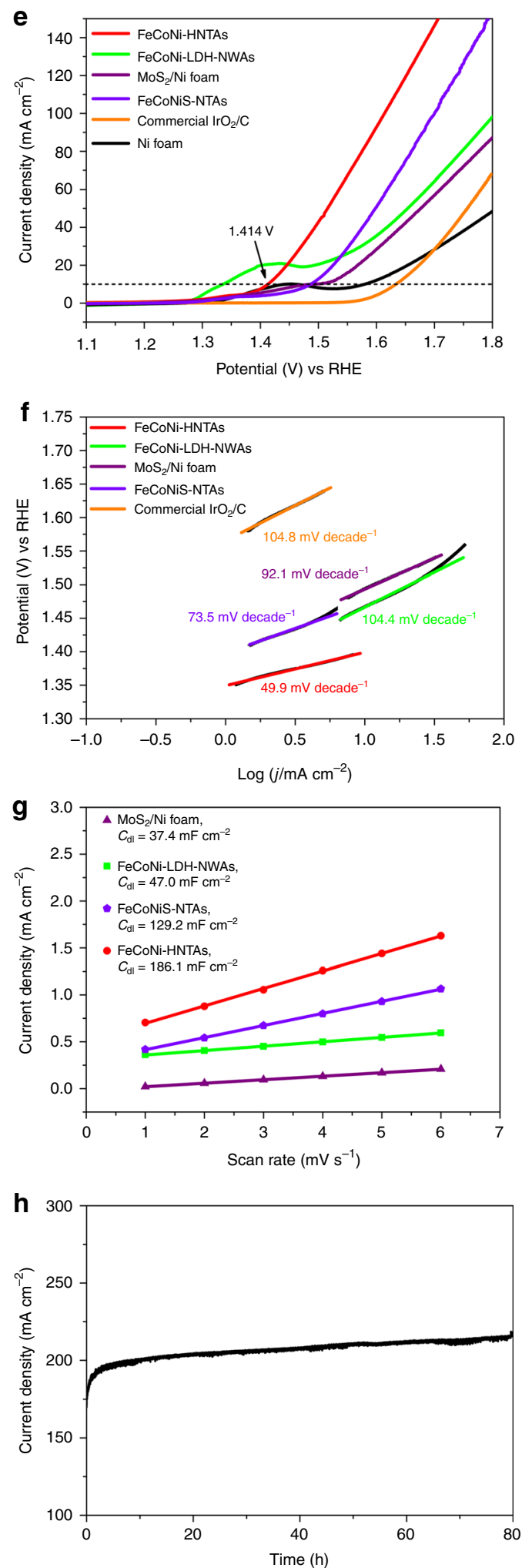

Fig. 5 HER and OER electrocatalytic performance. a, e Polarization plots for HER and OER processes in $1 \mathrm{M} \mathrm{KOH}$ electrolyte. Scan rate: $1 \mathrm{mV} \mathrm{s}{ }^{-1}$. b, $\mathbf{f}$ Tafel curves for HER and OER processes showing the reaction kinetics. Scan rate: $1 \mathrm{mV} \mathrm{s}^{-1} . \mathbf{c}, \mathbf{g} C_{\mathrm{dl}}$ measurements for HER and OER processes. $\mathbf{d}, \mathbf{h}$ Chronoamperometric measurements $(i-t)$ recorded on FeCoNi-HNTAs for $80 \mathrm{~h}$ at the steady potentials of $-0.326 \mathrm{~V}$ vs. RHE for HER and $1.796 \mathrm{~V}$ vs. RHE for OER, respectively 
catalytic active sites for HER. As for the durability of FeCoNiHNTAs, we carried out two sorts of measurements via chronoamperometry and galvanic pulse method to elucidate the continuous polarization ability and structural recoverability ${ }^{27}$. Figure 5d illustrates almost steady current density of near 200 $\mathrm{mA} \mathrm{cm}{ }^{-2}$ during an 80 -h chronoamperometry running. Meanwhile, periodic galvanic pulses recorded on FeCoNi-HNTAs at two different current density of $100 \mathrm{~mA} \mathrm{~cm}^{-2}$ and $200 \mathrm{~mA} \mathrm{~cm}^{-2}$ can be sustained for $30 \mathrm{~h}$ (Supplementary Fig. 18a). Apparently, the current density maintains almost unchanged, indicating the fascinating structural recoverability of FeCoNi-HNTAs due to the intrinsic structural superiority of hollow morphology. Moreover, Faradaic efficiency of the HER process over FeCoNi-HNTAs should also be evaluated as a crucial performance index. We employed a gas chromatography to monitor the amount of evolved $\mathrm{H}_{2}$ and the theoretical quantity of $\mathrm{H}_{2}$ at the current density of $20 \mathrm{~mA} \mathrm{~cm}^{-2}$ for $120 \mathrm{~min}$ continuously was calculated by the Faraday law. The comparison between the theoretical and experimental data (Supplementary Fig. 19a and Supplementary Table 3) presents a satisfying Faradaic efficiency of $99.7 \%$ for HER process, demonstrating that the measured electrocatalytic cathodic current stems exclusively from water reduction.

As the major barrier of water splitting, OER hinders efficiency promotion of overall water splitting. A high-performance electrode plays a pivotal role in overcoming the large overpotential to drive the reaction. We also used FeCoNi-HNTAs to electrocatalyze OER and thus assess the performance. FeCoNiHNTAs demonstrates the overpotential $\left(\eta_{\mathrm{OER}}\right)$ at the current density of $10 \mathrm{~mA} \mathrm{~cm}^{-2}$ can reach as low as $184 \mathrm{mV}$ (Fig. 5e), which achieves a great success as an electrocatalyst with low overpotential for OER. Markedly, polarization capability of FeCoNi-HNTAs is much higher than other contrastive samples (Supplementary Fig. 15b), especially for commercial $\mathrm{IrO}_{2} / \mathrm{C}$ $\left(\eta_{\mathrm{OER}} \approx 400 \mathrm{mV}\right)$. Faster catalytic reaction kinetics and electron transfer over FeCoNi-HNTAs are demonstrated by low Tafel slope $\left(49.9 \mathrm{mV} \mathrm{dec}^{-1}\right.$, Fig. $\left.5 \mathrm{f}\right)$ and reaction resistance $(\approx 1 \mathrm{ohm}$, Supplementary Fig. 16b). In the meantime, the ECSA for OER is estimated by the value of $C_{\mathrm{dl}}$ (Fig. $5 \mathrm{~g}$ and Supplementary Fig. 17b, $\mathrm{d}, \mathrm{f}, \mathrm{h}$ ). The higher ECSA of FeCoNi-HNTAs, $4652.5 \mathrm{~cm}^{2}$, further proves the compositional and structural advantages in exposure of catalytic active sites. Moreover, FeCoNi-HNTAs could maintain 80-h activity for holding the current density of around $200 \mathrm{~mA} \mathrm{~cm}^{-2}$ with slight increase (Fig. 5h) and 30-h structural recoverability during recurrent galvanic pulses between 100 and $200 \mathrm{~mA} \mathrm{~cm}^{-2}$ (Supplementary Fig. 18b). To prove the percent conversion from anodic current to $\mathrm{O}_{2}$ on FeCoNi-HNTAs, OER Faradaic efficiency was studied (Supplementary Fig. 19b and
Supplementary Table 3) and exhibited a reasonable value of $90.9 \%$, which was attributed to the complicated process of fourelectron transfer and the existence of oxidation current.

After 1000 HER and OER cycles, we collected and characterized the FeCoNi-HNTAs electrodes to identify the compositional and structural changes. As it is shown in Supplementary Fig. 20, it is unchanged for the crystal structures of FeCoNi-HNTAs after HER and OER cycles, similar to the as-prepared sample. SEM images (Supplementary Fig. 21a, b) show that nanotube array structures and uneven surfaces can be maintained and the size of a single nanotube stays the same as the initial one. The (101) planes of $1 \mathrm{~T}^{\prime} \mathrm{MoS}_{2}$ with aligned arrangement and the (222) lattice fringes of $(\mathrm{Co}, \mathrm{Fe}, \mathrm{Ni})_{9} \mathrm{~S}_{8}$ are observed in HRTEM images (Supplementary Fig. 21c, d), in accordance with the corresponding XRD patterns. EDX mapping spectra (Supplementary Fig. 22) further confirmed the uniform distribution of the seven elements. Compared with the as-prepared sample, the ratios of elements illustrated by EDX spectra (Supplementary Fig. 23) barely changed except for slightly increasing amount of oxygen after OER cycles. Moreover, the comparisons of smoothing XPS spectra of $\mathrm{Fe}, \mathrm{Co}$, and $\mathrm{Ni} 2 \mathrm{p}$ regions of FeCoNi-HNTAs before and after electrochemical measurements (Supplementary Fig. 24a, b, c) were made for the changes of $\mathrm{Fe}, \mathrm{Co}$, and $\mathrm{Ni}$ chemical states. As a result, HER process is conducive to the stabilization of valence states and there are hardly any shifts for $\mathrm{Fe}, \mathrm{Co}$, and $\mathrm{Ni} 2 \mathrm{p}$ peaks. However, small upshifts (about $0.3 \mathrm{eV}$ ) are observed for the peaks of $\mathrm{Fe}, \mathrm{Co}$, and $\mathrm{Ni} 2 \mathrm{p}$ regions of $\mathrm{FeCoNi}-\mathrm{HNTAs}$ after OER cycles, demonstrating in situ low-level oxidation of $\mathrm{Fe}, \mathrm{Co}$, Ni-based sulfides in the OER process, which is accordance with the EDX results. As for $1 \mathrm{~T}^{\prime} \mathrm{MoS}_{2}$, the two distinctive peaks of Mo $3 \mathrm{~d}_{5 / 2}$ and $3 \mathrm{~d}_{3 / 2}$ regions remain the same positions after HER and OER cycles (Supplementary Fig. 24d), which directly proves that this hybrid system plays a vital role in stabilizing $1 \mathrm{~T}^{\prime} \mathrm{MoS}_{2}{ }^{21}$. In accordance with the above results of characterizations after electrochemcial measurements, this hybrid system is quite robust and practical for electrocatalytic process of water oxidation and reduction, raising the hope of industrialization.

As a promising bifunctional electrocatalyst, FeCoNi-HNTAs were also employed to function as cathode and anode simultaneously incorporated with a configuration containing 1 $\mathrm{M} \mathrm{KOH} \mathrm{media} \mathrm{for} \mathrm{overall} \mathrm{water} \mathrm{splitting} \mathrm{(OWS)} \mathrm{at} \mathrm{room}$ temperature. Impressively, the electrodes exhibit prominent activity in this two-electrode system, requiring $1.429 \mathrm{~V}$ ( $\left.E_{\mathrm{OWS}}\right)$ of the cell voltage to drive a current density of $10 \mathrm{~mA} \mathrm{~cm}^{-2}$ (Fig. 6a), which demonstrates superior electrocatalytic activity than other electrodes (Supplementary Fig. 25). Compared with commercial $\mathrm{IrO}_{2} / \mathrm{C}-\mathrm{Pt} / \mathrm{C}$ couple $\left(E_{\mathrm{Ows}} \approx 1.58 \mathrm{~V}\right)$,
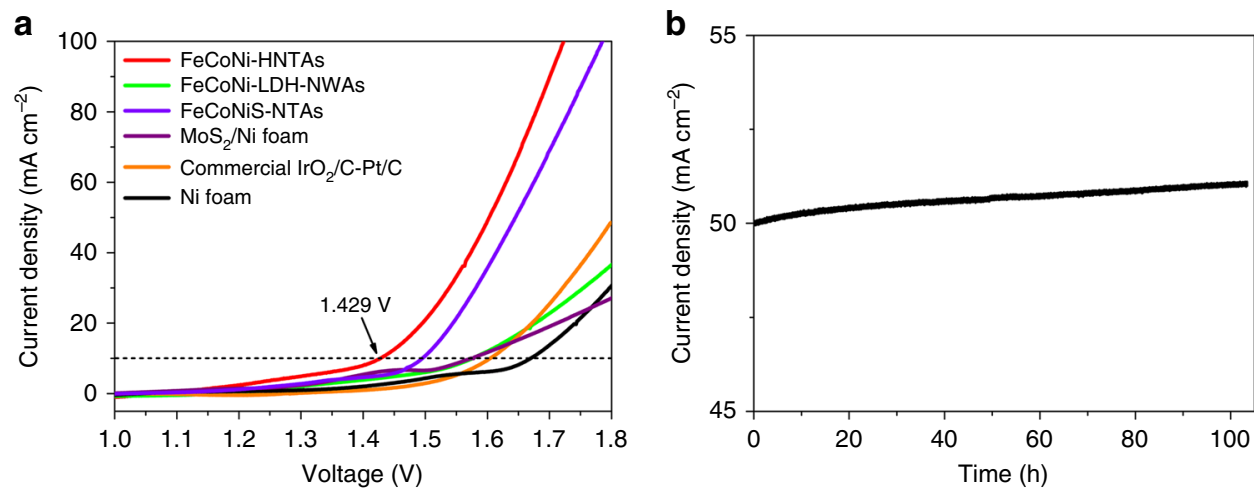

Fig. 6 Evaluation of the performance over FeCoNi-HNTAs for overall water splitting. a Polarization plots in $1 \mathrm{M} \mathrm{KOH}$ electrolyte with a typical two-electrode set-up. Scan rate: $1 \mathrm{mV} \mathrm{s}^{-1}$. b Chronoamperometric response recorded on FeCoNi-HNTAs at a constant cell voltage of $1.59 \mathrm{~V}$ 
FeCoNi-HNTAs elucidate the overwhelming activity and excellent ability for high-current operations. The long-playing stability measurement (Fig. 6b), maintaining current density of about 50 $\mathrm{mA} \mathrm{cm}{ }^{-2}$ for more than $100 \mathrm{~h}$, illustrates the great potential of FeCoNi-HNTAs for commercial utilization to replace noblemetal materials, which show a continuous degradation for a constant cell voltage operation (Supplementary Fig. 26). The overall water splitting process via chronoamperometric method at $1.55 \mathrm{~V}$ of the cell voltage for about $1.5 \mathrm{~min}$ was recorded in Supplementary Movie 1 , where $\mathrm{H}_{2}$ and $\mathrm{O}_{2}$ bubbles escaped continuously from surface of the left and the right electrode, respectively. This applicable testing offers a prospective evaluation of the feasibility for applying FeCoNi-HNTAs electrode into practical water splitting system.

EXAFS analysis for phase stability of $1 \mathrm{~T}^{\mathbf{x}} \mathbf{M o S}_{2}$. It has been evidenced that metallic $1 \mathrm{~T}^{\prime} \mathrm{MoS}_{2}$ is metastable with higher ground-state energy than its semiconducting $2 \mathrm{H}$ counterpart ${ }^{46}$. If there are some destabilizing factors affecting the $1 \mathrm{~T}^{\prime}$ phase, such as high temperature, it preferentially transforms into $2 \mathrm{H}$ phase, which is thermodynamically stable ${ }^{47}$. Therefore, we constructed this hybrid nanostructure to stabilize $1 \mathrm{~T}^{\prime} \mathrm{MoS}_{2}$, making it provide persistent functionality during electrocatalytic processes. To clarify the stability of $1 \mathrm{~T}^{\prime} \mathrm{MoS}_{2}$ in HER and OER electrocatalysis, we performed both ex situ and in situ EXAFS at Mo K-edge for FeCoNi-HNTAs. The in situ XANES spectra from EXAFS (Fig. 7a, c) and corresponding FT profiles (Fig. 7b, d) in R-space of FeCoNi-HNTAs at as-prepared and ongoing electrocatalytic states were carried out at different potentials during potentiostatic HER and OER measurements. It is noteworthy that the positions of Mo-Mo bond peaks for $1 \mathrm{~T}^{\prime} \mathrm{MoS}_{2}$ are unchanged during the applied HER and OER processes compared to that of the initial sample, indicating $1 \mathrm{~T}^{\prime} \mathrm{MoS}_{2}$ in our hybrid system enables splendid stability at both reduction and oxidation potentials. According to ex situ EXAFS experiments (Supplementary Fig. 27, 28, Supplementary Table 1), $\mathrm{MoS}_{2}$ in FeCoNi-HNTAs after galvanostatic scan of HER and OER (Supplementary Note 1) still kept $1 \mathrm{~T}$ ' phase, which was in accordance with the in situ EXAFS data. However, OER operations bring about the increasing proportion of oxidized $\mathrm{MoS}_{2}$ that are positively related to the potentials. At the meantime, long-term electrolysis running can also generate oxidized $\mathrm{MoS}_{2}$, suggesting that 1T'MoS affects both half reactions of water splitting. In this system, $\mathrm{FeCoNi}$ LDH-NWAs can coordinate with HZH to form complexes for protection of $1 \mathrm{~T}^{\prime} \mathrm{MoS}_{2}{ }^{21}$. Supplementary Fig. 29 exhibits the representative core-shell nanostructure after 1000 OER cycles. Integrated with the corresponding XRD pattern (Supplementary Fig. 18), the core can be indexed to $1 \mathrm{~T}^{\prime} \mathrm{MoS}_{2}$ with the zigzag chains and the shell matching with the amorphous component layer. This strategy has been successfully developed for stabilizing $1 \mathrm{~T}^{\prime} \mathrm{MoS}_{2}$, which can be considered as a forward step toward the actual use of $1 \mathrm{~T}^{\prime} \mathrm{MoS}_{2}$.

\section{Discussion}

In summary, employing FeCoNi-LDH-NWAs as the selfsacrificing template and precursor, we have successfully synthesized FeCoNi-HNTAs using Ni foam as the substrate through a facile solvothermal method as a highly active and stable bifunctional electrocatalytst for overall water splitting in alkaline electrolyte. Notably, this complex polymetallic sulfides system
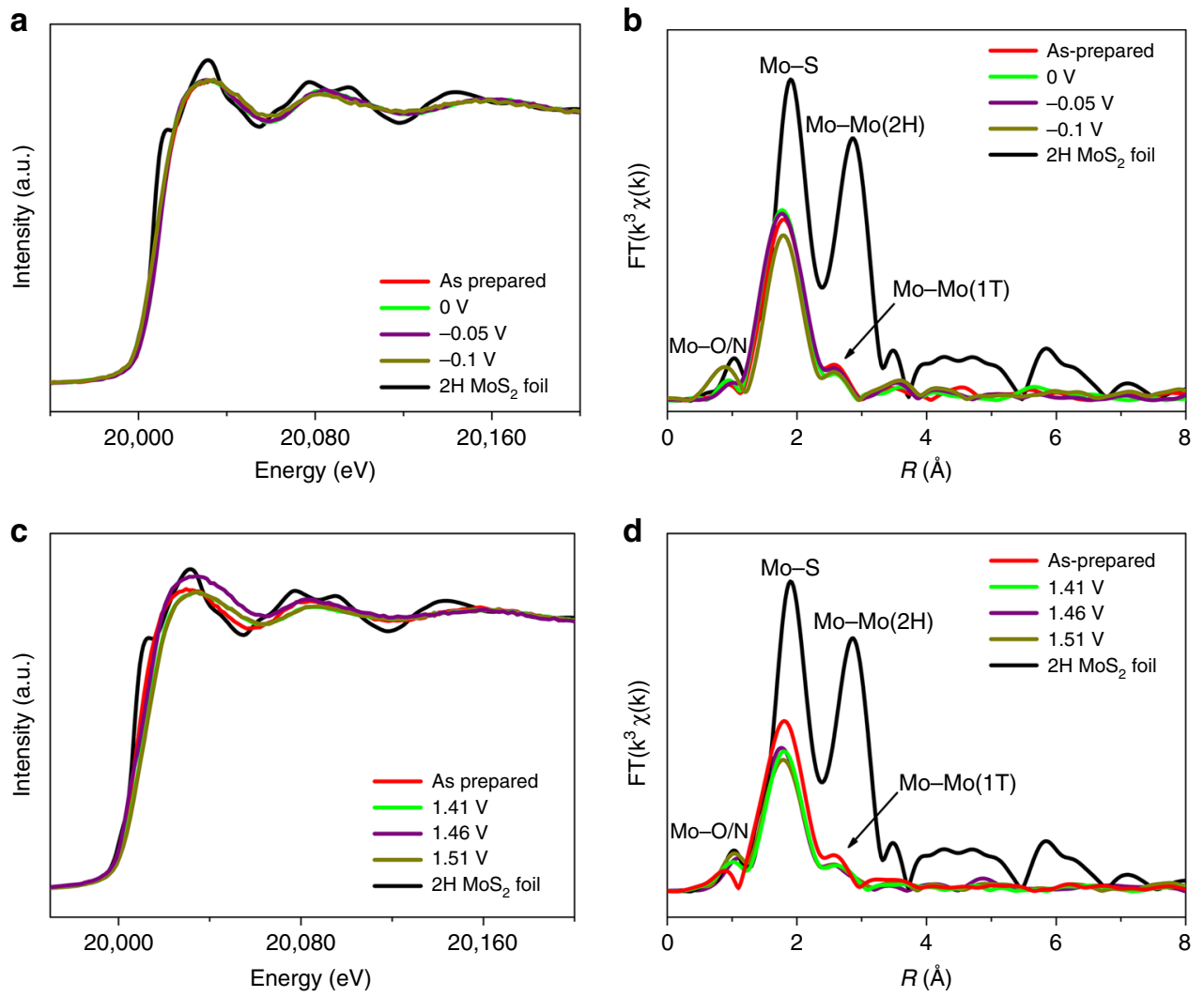

Fig. 7 In situ EXAFS characterization showing phase stability of $1 T^{\prime} M_{0} S_{2} \mathbf{a}, \mathbf{c}$, and $\mathbf{b}, \mathbf{d}$, The normalized in situ XANES spectra and the corresponding $k^{3}$ weighted FT profiles in R-space from EXAFS at Mo K-edge collected on as-synthesized FeCoNi-HNTAs in the processes of potentiostatic HER and OER measurements with different voltages $(0,-0.05$, and $-0.1 \mathrm{~V}$ vs. RHE for HER and $1.41,1.46$, and $1.51 \mathrm{~V}$ vs. RHE for OER), respectively 
leverages the multiple advantages of chemical compositions, geometric structural features, and substrate characteristics to demonstrate remarkably low overpotentials and long-term durability for electrolysis. Our comprehensive experimental explorations exhibit the compositional origins of the excellent electrocatalytic performance, which are proven to be the synergistic effects among $\mathrm{Fe}, \mathrm{Co}$, and $\mathrm{Ni}$ ions as well as proliferated catalytic active sites and superb conductivity of $1 \mathrm{~T}^{\prime} \mathrm{MoS}_{2}$. On the other hand, under-electrolyte superaerophobicity facilitates the disengagement of as-formed gas bubbles from electrode surface with ease, contributing to a significant boost in water splitting effectiveness. It is believed that this system-optimized hybrid electrode holds great promise for large-scale production and practical utilizations, which opens up a fascinating way to create high-efficiency electrodes for energy conversion technologies.

\section{Methods}

Synthesis of FeCoNi-LDH-NWAs. In a typical synthesis, $121.2 \mathrm{mg} \mathrm{Fe}\left(\mathrm{NO}_{3}\right)_{3} \cdot 9 \mathrm{H}_{2} \mathrm{O}$, $436.5 \mathrm{mg} \mathrm{Co}\left(\mathrm{NO}_{3}\right)_{2} \cdot 6 \mathrm{H}_{2} \mathrm{O}, 450 \mathrm{mg}\left(\mathrm{NH}_{2}\right)_{2} \mathrm{CO}$, and $222 \mathrm{mg} \mathrm{NH}{ }_{4} \mathrm{~F}$ were dissolved into $40 \mathrm{ml}$ ultrapure water and moved into a $45 \mathrm{ml}$ teflon-lined autoclave with steel shell. A piece of Ni foam $\left(1 \times 3 \mathrm{~cm}\right.$, thickness: $1.5 \mathrm{~mm}$, bulk density: $\left.0.3 \mathrm{~g} / \mathrm{cm}^{3}\right)$ was cleaned ultrasonically first with ethanol $(20 \mathrm{ml})$, then with $3 \mathrm{M} \mathrm{HCl}$ aqueous solution $(20 \mathrm{ml})$ for $15 \mathrm{~min}$, and washed subsequently with deionized water for three times. The as-prepared $\mathrm{Ni}$ foam above was immersed into the above autoclave and exactly stuck at the center of the autoclave vertically. The autoclave was sealed and then heated at $120^{\circ} \mathrm{C}$ for $10 \mathrm{~h}$. The obtained electrode was cleaned with ethanol three times and dried in vacuum at room temperature for further characterizations and next step reaction. The synthetic methods of NiCo-LDH-NWAs and NiFe-LDH-NSAs were the same as that of FeCoNi-LDH-NWAs, except that no adding iron source for NiCo-LDH-NWAs and no adding cobalt source as well as increasing amount of iron source to $606 \mathrm{mg}$ for NiFe-LDH-NSAs, respectively. When focusing on the details of reaction process, fluoride ions were added into the reaction solvent to coordinate with the metal ions, resulting in slow release of the metal ions and promotion of nucleus formation on the substrate. Then the released metal ions combined with $\mathrm{CO}_{3}{ }^{2-}$ and $\mathrm{OH}^{-}$generated from the hydrolysis of urea forming polymetal carbonate hydroxides.

Synthesis of FeCoNi-HNTAs. First, $15 \mathrm{mg}$ of $\left(\mathrm{NH}_{4}\right)_{2} \mathrm{MoS}_{4}$ were dissolved in $38 \mathrm{ml}$ of N,N-dimethylformamide (DMF) and stirred for $10 \mathrm{~min}$ to make solution homogeneous. Then $2 \mathrm{ml} \mathrm{HZH}$ (volume fraction, 85\%) was introduced dropwise into the foregoing solution with vigorously stirring. The mixed solution for growing hybrid nanotubes was transferred into a $45 \mathrm{ml}$ teflon-lined autoclave with steel shell and FeCoNi-LDH-NWAs was submerged into the above solution and exactly stuck at the direction of autoclave diameter vertically. The autoclave was sealed and then heated at $200^{\circ} \mathrm{C}$ for $10 \mathrm{~h}$. When the system was cooled down, this obtained electrode was cleaned with ethanol three times and dried in vacuum at room temperature for further characterizations. The synthetic methods of $\mathrm{CoNi}$ HNTAs and NiFe-HNSAs were the same as that of FeCoNi-HNTAs, except that the precursor of FeCoNi-LDH-NWAs was replaced by NiCo-LDH-NWAs and NiFe-LDH-NSAs, respectively.

Synthesis of $\mathrm{MoS}_{2} / \mathrm{Ni}$ foam. The synthetic method of $\mathrm{MoS}_{2} / \mathrm{Ni}$ foam was the same as that of the FeCoNi-HNTAs, except that the precursor of FeCoNi-LDHNWAs was replaced by the cleaned Ni foam.

Synthesis of FeCoNiS-NTAs. The synthetic method of FeCoNiS-NTAs was the same as that of the FeCoNi-HNTAs, except that the precursor of $\left(\mathrm{NH}_{4}\right)_{2} \mathrm{MoS}_{4}$ was replaced by $20 \mathrm{mg}$ of TAA.

\footnotetext{
Material characterizations. The morphologies and structures of as-prepared samples were characterized by field-emission scanning electron microscopy, transmission electron microscopy, high-resolution transmission electron microscopy, and scanning transmission electron microscopy (FESEM: Hitachi, SU8010, $10 \mathrm{kV}$; TEM: Hitachi, H7700, $100 \mathrm{kV}$; HRTEM and STEM: JEOL, JEM-2100, 200 $\mathrm{kV}$ and FEI, Tecnai G2 F20, $200 \mathrm{kV}$ ). Atomic resolution aberration-corrected scanning transmission electron microscopy (AC-STEM) images were carried out by a JEOL ARM200F at $200 \mathrm{kV}$ with double hexapole Cs correctors andcold field emission gun. Energy-disperse X-ray spectra (EDX) and elemental mapping spectra were performed with the same instruments as HRTEM. X-ray diffraction (XRD) patterns were measured by using a Bruker D8 Advance X-ray diffractometer equipped with $\mathrm{Cu} \mathrm{Ka}$ radiation $(\lambda=1.5418 \AA$ ). X-ray photoelectron spectra (XPS) were performed by using a PHI Quantera SXM spectrometer with monochromatic $\mathrm{Al} \mathrm{Ka} \mathrm{X}$-ray sources $(1486.6 \mathrm{eV})$ at $2.0 \mathrm{kV}$ and $20 \mathrm{~mA}$. The wetting ability of surface of the electrode was characterized by surveying the contact angles of electrolyte, $1 \mathrm{M} \mathrm{KOH}$ solution. In the typical measurement, a $3 \mu \mathrm{l}$ droplet of $1 \mathrm{M}$
}

$\mathrm{KOH}$ solution was dropped on surface of the electrode and the contact angle was measured by a Dataphysics OCA20 system at room temperature in ambient air. The contact angles of gas bubbles under electrolyte were tested by the method of captive bubble using Dataphysics OCA20 system. The observed equilibrium contact angles were defined as the pinned bubbles with liquid around on surface of the electrode, and the interface of liquid/gas contacts with the interface of solid/liquid across the three phase contact interfaces. The volume of the measured bubble was taken around $3 \mu$ l. When measuring the advancing angle and receding angle, it is needed to increase and then decrease a constant volume (ca. $2 \mu \mathrm{l}$ ) of the measured bubbles. Each contact angle measurement was repeated more than 5 times. The images of hydrogen and oxygen bubbles release were obtained by a high-speed charge-coupled device camera (i-SPEED, OLYMPUS) equipped with a microscope (SZ-CTC, OLYMPUS). A fiber optic illuminator system (Multi-Position, Nikon) provides the illumination. The ex situ and in situ synchrotron radiation-based extended X-ray absorption fine structure (EXAFS) measurements at Mo K-edge were carried out at the beamline 14W1 in 1W1B station in Beijing Synchrotron Radiation Facility (BSRF). A double-crystal Si (111) monochromator monochromatized the X-ray. The energy calibration was performed by using a Mo metal foil at Mo K-edge. Higher harmonics was removed by detuning the monochromator. The obtained data were calculated and processed based on the WinXAS3.1 program ${ }^{48}$. Phase-shift functions and theoretical amplitudes were calculated by the FEFF8.2 code and the parameters of crystal structure of the standard $2 \mathrm{H} \mathrm{MoS}_{2}$ foil ${ }^{49}$. The synchrotron radiation-based soft X-ray absorption spectroscopy (sXAS) tests were carried out in 4B7B station in Beijing Synchrotron Radiation Facility (BSRF).

Electrocatalytic measurements. The electrocatalytic measurements were performed at room temperature with a Princeton PASTAT4000 and a Chenhua CHI660e instrument in $1 \mathrm{M} \mathrm{KOH}$ media. The HER and OER electrocatalytic processes were investigated in a typical three-electrode configuration. $\mathrm{A} \mathrm{Ag} / \mathrm{AgCl}$ electrode with saturated $\mathrm{KCl}-\mathrm{AgCl}$ solution and a graphite rod were utilized as the reference and counter electrodes, respectively. The as-prepared electrodes supported on $\mathrm{Ni}$ foam were utilized as the working electrode. In this three-electrode configuration, the reversible hydrogen electrode (RHE) calibration was carried out in the $\mathrm{H}_{2}$-saturated $1 \mathrm{M} \mathrm{KOH}$ solution using a Pt sheet as the working electrode. A single cycle of cyclic voltammetry was recorded at a scan rate of $1 \mathrm{mV} \mathrm{s}^{-1}$ and the average value of the two potentials where the current crossed line of zero value was considered as the potential of the calibration. In $1 \mathrm{M} \mathrm{KOH}$ electrolyte, $E(\mathrm{RHE})=E$ $(\mathrm{SCE})+1.012 \mathrm{~V}$. Before the measurements, the working electrode was tailored as a square piece with the working surface area of about $0.9 \mathrm{~cm}^{2}$ and immersed in the applied electrolyte for $12 \mathrm{~h}$ in vacuum to activate the electrode. For comparison, commercial Pt/C (20\%, loaded on Ni foam with $\left.1 \mathrm{mg} \mathrm{cm}^{-2}\right)$ and $\mathrm{IrO}_{2} / \mathrm{C}(20 \%$, loaded on Ni foam with $1 \mathrm{mg} \mathrm{cm}^{-2}$ ) were deployed for HER and OER catalysis. Besides, overall water splitting was measured in a typical two-electrode system utilizing the as-prepared electrodes as cathode and anode simultaneously. For HER and OER processes, the polarization curves and Tafel plots were characterized in the selected potential ranges at a scan rate of $1 \mathrm{mV} \mathrm{s}^{-1}$. The Nyquist plots of electrochemical impedance spectroscopy (EIS) was surveyed in the frequency range of $10 \mathrm{kHz}-100 \mathrm{mHz}$ at the open circuit voltage of HER and OER, respectively. The stability measurements $(i-t)$ were recorded for $80 \mathrm{~h}$ at a constant applied potential of $-0.326 \mathrm{~V}$ vs. RHE for HER and $1.796 \mathrm{~V}$ vs. RHE for OER, respectively. The cyclic voltammetry was carried out to assess electrochemical double-layer capacitance $\left(C_{\mathrm{dl}}\right)$ at no faradic processes six times at six different scan rates $(1,2,3,4,5,6$ $\mathrm{mV} \mathrm{s}^{-1}$ ). The obtained current densities at the selected potential have the linear relationship with the scan rates and the slopes of fitting curves were considered as the $C_{\mathrm{dl}}$. We applied the specific capacitance $\left(20-60 \mu \mathrm{F} \mathrm{cm}{ }^{-2}\right)$ of $40 \mu \mathrm{F} \mathrm{cm}^{-2}$ here to calculate the ECSA. According to the Eq. $(1)^{50}$

$$
\mathrm{ECSA}=\frac{C_{\mathrm{dl}}}{40 \mu \mathrm{F} / \mathrm{cm}^{2}} \mathrm{~cm}_{\mathrm{ECSA}}^{2} .
$$

the ECSA values were roughly obtained. The periodic galvanic pulses was achieved to prove the structural recoverability and stability of the material between two different current density of $100 \mathrm{~mA} \mathrm{~cm}^{-2}$ and $200 \mathrm{~mA} \mathrm{~cm}^{-2}$ with an iteration period of $2000 \mathrm{~s}$. Moreover, gas chromatography (Shimadzu, GC-2014C) was employed to determine the experimentally evolved amount of $\mathrm{H}_{2}$ and $\mathrm{O}_{2}$ during $120 \mathrm{~min}$ in electrocatalytic processes for the Faradaic efficiency measurements. It was hypothesized for the theoretical values that the whole current transfers into the gas production during the reaction. We also calculate the theoretical quantity of $\mathrm{H}_{2}$ and $\mathrm{O}_{2}$ by using the Faraday law based on an $i-t$ curve at the constant current density of $20 \mathrm{~mA} \mathrm{~cm}^{-2}$ for $120 \mathrm{~min}$, which demonstrated that the transformation of $96485.4 \mathrm{C}$ charge causes 1 equivalent of reaction. As for overall water splitting, the polarization curves were performed at a scan rate of $1 \mathrm{mV} \mathrm{s}^{-1}$.

Chronoamperometric curves of FeCoNi-HNTAs and commercial $\mathrm{IrO}_{2} / \mathrm{C}-\mathrm{Pt} / \mathrm{C}$ couple electrode were measured at the constant cell voltages of 1.59 and $1.8 \mathrm{~V}$ respectively.

Data availability. The authors make a statement that the data presented by this article are available from the corresponding author on reasonable requests. 
Received: 7 February 2018 Accepted: 25 May 2018

Published online: 22 June 2018

\section{References}

1. Aricò, A. S., Bruce, P., Scrosati, B., Tarascon, J.-M. \& Van Schalkwijk, W. Nanostructured materials for advanced energy conversion and storage devices. Nat. Mater. 4, 366-377 (2005).

2. Faber, M. S. \& Jin, S. Earth-abundant inorganic electrocatalysts and their nanostructures for energy conversion applications. Energy Environ. Sci. 7, 3519-3542 (2014).

3. Chu, S., Cui, Y. \& Liu, N. The path towards sustainable energy. Nat. Mater. 16, 16-22 (2017).

4. Khaselev, O. \& Turner, J. A. A monolithic photovoltaic-photoelectrochemical device for hydrogen production via water splitting. Science 280, 425-427 (1998).

5. Mallouk, T. E. Water electrolysis: divide and conquer. Nat. Chem. 5, 362-363 (2013).

6. Roger, I., Shipman, M. A. \& Symes, M. D. Earth-abundant catalysts for electrochemical and photoelectrochemical water splitting. Nat. Rev. Chem. 1, 0003 (2017).

7. Jiao, Y., Zheng, Y., Jaroniec, M. \& Qiao, S. Z. Design of electrocatalysts for oxygen-and hydrogen-involving energy conversion reactions. Chem. Soc. Rev. 44, 2060-2086 (2015).

8. Ng, J. W. D. et al. Gold-supported cerium-doped $\mathrm{NiO}_{x}$ catalysts for water oxidation. Nat. Energy 1, 16053 (2016).

9. Xia, B. Y. et al. A metal-organic framework-derived bifunctional oxygen electrocatalyst. Nat. Energy 1, 15006 (2016).

10. Voiry, D. et al. Enhanced catalytic activity in strained chemically exfoliated $\mathrm{WS}_{2}$ nanosheets for hydrogen evolution. Nat. Mater. 12, 850-855 (2013).

11. Long, X. et al. Metallic iron-nickel sulfide ultrathin nanosheets as a highly active electrocatalyst for hydrogen evolution reaction in acidic media. J. Am. Chem. Soc. 137, 11900-11903 (2015).

12. Zhang, B. et al. Homogeneously dispersed multimetal oxygen-evolving catalysts. Science 352, 333-337 (2016).

13. Yin, Y. et al. Contributions of phase, sulfur vacancies, and edges to the hydrogen evolution reaction catalytic activity of porous molybdenum disulfide nanosheets. J. Am. Chem. Soc. 138, 7965-7972 (2016).

14. Liu, Y. et al. Self-optimizing, highly surface-active layered metal dichalcogenide catalysts for hydrogen evolution. Nat. Energy 2, 17127 (2017).

15. Voiry, D. et al. Conducting $\mathrm{MoS}_{2}$ nanosheets as catalysts for hydrogen evolution reaction. Nano. Lett. 13, 6222-6227 (2013)

16. Liu, Y. et al. Ultrathin $\mathrm{Co}_{3} \mathrm{~S}_{4}$ nanosheets that synergistically engineer spin states and exposed polyhedra that promote water oxidation under neutral conditions. Angew. Chem. Int. Ed. 127, 11383-11387 (2015).

17. Feng, L.-L. et al. High-index faceted $\mathrm{Ni}_{3} \mathrm{~S}_{2}$ nanosheet arrays as highly active and ultrastable electrocatalysts for water splitting. J. Am. Chem. Soc. 137, 14023-14026 (2015).

18. Lu, Z. et al. Ultrahigh hydrogen evolution performance of under-water "superaerophobic" $\mathrm{MoS}_{2}$ nanostructured electrodes. Adv. Mater. 26, 2683-2687 (2014).

19. Xu, W., Lu, Z., Wan, P., Kuang, Y. \& Sun, X. High-performance water electrolysis system with double nanostructured superaerophobic electrodes. Small 12, 2492-2498 (2016).

20. Sun, M.-H. et al. Applications of hierarchically structured porous materials from energy storage and conversion, catalysis, photocatalysis, adsorption, separation, and sensing to biomedicine. Chem. Soc. Rev. 45, 3479-3563 (2016).

21. Li, H. et al. Amorphous nickel-cobalt complexes hybridized with 1T-phase molybdenum disulfide via hydrazine-induced phase transformation for water splitting. Nat. Commun. 8, 15377 (2017).

22. Voiry, D., Mohite, A. \& Chhowalla, M. Phase engineering of transition metal dichalcogenides. Chem. Soc. Rev. 44, 2702-2712 (2015).

23. Putungan, D. B., Lin, S.-H. \& Kuo, J.-L. A first-principles examination of conducting monolayer $1 \mathrm{~T}^{\prime}-\mathrm{MX}_{2}(\mathrm{M}=\mathrm{Mo}, \mathrm{W} ; \mathrm{X}=\mathrm{S}, \mathrm{Se}, \mathrm{Te})$ : promising catalysts for hydrogen evolution reaction and its enhancement by strain. Phys. Chem. Chem. Phys. 17, 21702-21708 (2015).

24. Ding, Q., Song, B., Xu, P. \& Jin, S. Efficient electrocatalytic and photoelectrochemical hydrogen generation using $\mathrm{MoS}_{2}$ and related compounds. Chem 1, 699-726 (2016).

25. Friebel, D. et al. Identification of highly active $\mathrm{Fe}$ sites in $(\mathrm{Ni}, \mathrm{Fe}) \mathrm{OOH}$ for electrocatalytic water splitting. J. Am. Chem. Soc. 137, 1305-1313 (2015).

26. Burke, M. S., Kast, M. G., Trotochaud, L., Smith, A. M. \& Boettcher, S. W. Cobalt-iron (oxy) hydroxide oxygen evolution electrocatalysts: the role of structure and composition on activity, stability, and mechanism. J. Am. Chem. Soc. 137, 3638-3648 (2015).
27. Zhao, S. et al. Ultrathin metal-organic framework nanosheets for electrocatalytic oxygen evolution. Nat. Energy 1, 16184 (2016)

28. Jiang, J. et al. General synthesis of large-scale arrays of one-dimensional nanostructured $\mathrm{Co}_{3} \mathrm{O}_{4}$ directly on heterogeneous substrates. Cryst. Growth Des. 10, 70-75 (2009).

29. Yang, Q. et al. Hierarchical $\mathrm{Co}_{3} \mathrm{O}_{4}$ nanosheet@ nanowire arrays with enhanced pseudocapacitive performance. RSC Adv. 2, 1663-1668 (2012).

30. Sasikumar, G., Ihm, J. W. \& Ryu, H. Optimum nafion content in PEM fuel cell electrodes. Electrochim. Acta 50, 601-605 (2004).

31. Zhang, X. et al. Co/Co $\mathrm{S}_{8} @ \mathrm{~S}, \mathrm{~N}$-doped porous graphene sheets derived from $\mathrm{S}$, $\mathrm{N}$ dual organic ligands assembled Co-MOFs as superior electrocatalysts for full water splitting in alkaline media. Nano Energy 30, 93-102 (2016).

32. Yin, Y. et al. Formation of hollow nanocrystals through the nanoscale Kirkendall effect. Science 304, 711-714 (2004).

33. Knez, M. et al. Monocrystalline spinel nanotube fabrication based on the Kirkendall effect. Nat. Mater. 5, 627-631 (2006).

34. Wypych, F., Solenthaler, C., Prins, R. \& Weber, T. Electron diffraction study of intercalation compounds derived from $1 \mathrm{~T}-\mathrm{MoS}_{2}$. J. Am. Chem. Soc. 144, 430-436 (1999).

35. Chauke, H. R., Nguyen-Manh, D., Ngoepe, P. E., Pettifor, D. G. \& Fries, S. G Electronic structure and stability of the pentlandites $\mathrm{Co}_{9} \mathrm{~S}_{8}$ and $(\mathrm{Fe}, \mathrm{Ni})_{9} \mathrm{~S}_{8}$. Phys. Rev. B 66, 155105 (2002).

36. Liu, Q. et al. Gram-scale aqueous synthesis of stable few-layered $1 \mathrm{~T}-\mathrm{MoS}_{2}$ : applications for visible-light-driven photocatalytic hydrogen evolution. Small 11, 5556-5564 (2015).

37. Kappera, R. et al. Phase-engineered low-resistance contacts for ultrathin $\mathrm{MoS}_{2}$ transistors. Nat. Mater. 13, 1128-1134 (2014).

38. Biesinger, M. C. et al. Resolving surface chemical states in XPS analysis of firs row transition metals, oxides and hydroxides: $\mathrm{Cr}, \mathrm{Mn}, \mathrm{Fe}, \mathrm{Co}$ and $\mathrm{Ni}$. Appl. Surf. Sci. 257, 2717-2730 (2011)

39. Bai, Y. et al. Universal synthesis of single-phase pyrite $\mathrm{FeS}_{2}$ nanoparticles, nanowires, and nanosheets. J. Phys. Chem. C. 117, 2567-2573 (2013).

40. Faber, M. S. et al. High-performance electrocatalysis using metallic cobalt pyrite $\left(\mathrm{CoS}_{2}\right)$ micro-and nanostructures. J. Am. Chem. Soc. 136, 10053-10061 (2014).

41. Liu, X. et al. Phase transformation and lithiation effect on electronic structure of $\mathrm{Li}_{\mathrm{X}} \mathrm{FePO}_{4}$ : An in-depth study by soft X-ray and simulations. J. Am. Chem. Soc. 134, 13708-13715 (2012).

42. Wang, J., Zhou, J., Hu, Y. \& Regier, T. Chemical interaction and imaging of single $\mathrm{Co}_{3} \mathrm{O}_{4}$ /graphene sheets studied by scanning transmission $\mathrm{X}$-ray microscopy and X-ray absorption spectroscopy. Energy Environ. Sci. 6 926-934 (2013).

43. Bao, J. et al. Ultrathin spinel-structured nanosheets rich in oxygen deficiencies for enhanced electrocatalytic water oxidation. Angew. Chem. Int. Ed. 127, 7507-7512 (2015)

44. Qiao, R. et al. Direct experimental probe of the $\mathrm{Ni}(\mathrm{II}) / \mathrm{Ni}(\mathrm{III}) / \mathrm{Ni}(\mathrm{IV})$ redox evolution in $\mathrm{LiNi}_{0 .}{ }_{5} \mathrm{Mn}_{1,5} \mathrm{O}_{4}$ electrodes. J. Phys. Chem. C. 119, 27228-27233 (2015).

45. Huang, Y. et al. Controllable underwater oil-adhesion-interface films assembled from nonspherical particles. Adv. Func. Mater. 21, 4436-4441 (2011).

46. Duerloo, K.-A. N., Li, Y. \& Reed, E. J. Structural phase transitions in twodimensional Mo-and W-dichalcogenide monolayers. Nat. Commun. 5, 4214 (2014).

47. Heising, J. \& Kanatzidis, M. G. Structure of restacked $\mathrm{MoS}_{2}$ and $\mathrm{WS}_{2}$ elucidated by electron crystallography. J. Am. Chem. Soc. 121, 638-643 (1999).

48. Ressler, T. WinXAS: a program for X-ray absorption spectroscopy data analysis under MS-Windows. J. Synchrotron Radiat. 5, 118-122 (1998).

49. Ankudinov, A. L., Ravel, B., Rehr, J. J. \& Conradson, S. D. Real-space multiplescattering calculation and interpretation of $\mathrm{x}$-ray-absorption near-edge structure. Phys. Rev. B 58, 7565 (1998).

50. Kibsgaard, J. \& Jaramillo, T. F. Molybdenum phosphosulfide: an active, acidstable, earth-abundant catalyst for the hydrogen evolution reaction. Angew. Chem. Int. Ed. 53, 14433-14437 (2014).

\section{Acknowledgements}

This work was supported by China Ministry of Science and Technology under Contract of 2017YFA0700101 and 2016YFA0202801 and National Natural Science Foundation of China $(21431003,21521091)$. We thank Dr. Lirong Zheng for providing the EXAFS tests in 1W1B station and Dr. Shuhu Liu, Dr. Jiaou Wang for offering sXAS tests in 4B7B station in Beijing Synchrotron Radiation Facility (BSRF)

\section{Author contributions}

X.W. supervised this study. X.W. and H.L. conceived the idea. H.L. planned and carried out the experiments, collected and analyzed the experimental data. S.C. and L.S. analyzed the ex situ and in situ EXAFS data. Y.Z. and X.S. collected the data of adhesive force and contact angle measurements. Q.H.Z. and L.G. performed AC-STEM characterizations. H 
L., X.J., Q.Z., and X.W. co-wrote the manuscript. All authors approve the final version of this article.

\section{Additional information}

Supplementary Information accompanies this paper at https://doi.org/10.1038/s41467018-04888-0.

Competing interests: The authors declare no competing interests.

Reprints and permission information is available online at http://npg.nature.com/ reprintsandpermissions/

Publisher's note: Springer Nature remains neutral with regard to jurisdictional claims in published maps and institutional affiliations. (c) Open Access This article is licensed under a Creative Commons Attribution 4.0 International License, which permits use, sharing, adaptation, distribution and reproduction in any medium or format, as long as you give appropriate credit to the original author(s) and the source, provide a link to the Creative Commons license, and indicate if changes were made. The images or other third party material in this article are included in the article's Creative Commons license, unless indicated otherwise in a credit line to the material. If material is not included in the article's Creative Commons license and your intended use is not permitted by statutory regulation or exceeds the permitted use, you will need to obtain permission directly from the copyright holder. To view a copy of this license, visit http://creativecommons.org/ licenses/by/4.0/.

(C) The Author(s) 2018 